\title{
Horizonte 2020: patrimonio cultural, un reto social
}

Horizonte 2020 es uno de los programas de innovación e investigación surgidos dentro de la estrategia de crecimiento de la Unión Europea para la década 2010-2020. Esta estrategia busca fomentar una economía inteligente, sostenible e integradora que mejore los niveles de empleo, de productividad y de cohesión social. En ese sentido, el programa considera que el patrimonio cultural es un recurso productivo de primer orden y quiere motivar un uso innovador del mismo. Para ello incluye una convocatoria de propuestas que trabajen en este sentido.

Laura Velasco García | Experta evaluadora de la Comisión Europea, Programa Horizonte 2020

URL de la contribución <www.iaph.es/revistaph/index.php/revistaph/article/view/3987>

Horizonte 2020, un programa de innovación e investigación que responde a la estrategia de crecimiento de la Unión Europea (2010-2020), se sustenta sobre tres pilares: abordar los principales retos sociales de Europa, promover el liderazgo industrial y reforzar la excelencia de su base científica. Para cada uno de estos pilares se ha identificado una serie de retos a alcanzar que reporten beneficios directos y tangibles a la población ${ }^{1}$.

Interesa especialmente cómo se entiende el patrimonio cultural en $\mathrm{H} 2020$ y el tipo de proyecto que se promueve. De manera concreta se hará referencia a los proyectos incluidos en el Reto 5: Acción por el clima, medio ambiente, eficiencia de recursos y materias primas dentro del Programa de Trabajo 2016-2017².

H2020 busca un uso innovador del patrimonio y lo considera un recurso productivo de primer orden. Su inclusión en el Reto 5 queda justificada al considerar que el patrimonio cultural de Europa está sufriendo un deterioro "medioambiental" como consecuencia de las actividades humanas (por ejemplo las turísticas), del cambio climático y de otras catástrofes naturales. Se plantea cómo una inversión moderada permitirá la generación de ingresos económicos y podrá tener beneficios directos y reales a nivel medioambiental y social. Los proyectos deben responder a la necesidad de fomentar una economía sostenible, a integrar la tecnología, la innovación social, la multiplicidad de actores y deben buscar soluciones para el futuro que fomenten las inversiones públicas y privadas ${ }^{3}$.
De manera concreta se incluye una convocatoria de propuestas denominada Hacia una economía verde, en la que se encuadra el topic ${ }^{4}$ SC5-2016-1017 Patrimonio cultural para un desarrollo sostenible, que busca la regeneración del territorio a través del patrimonio y que se ha concretado en dos líneas, una dedicada al territorio urbano (Heritage-led urban regeneration, 2016) y otra al territorio rural (Heritage-led rural regeneration, 2017). Se parte de la base de que tanto las ciudades como las zonas rurales de Europa conforman paisajes culturales de gran diversidad y forman parte de la identidad de cada país y de Europa en su conjunto. Se trata de un patrimonio vivo sobre el que se construye la sociedad actual pero que está enfrentándose a problemas económicos (desempleo), sociales (despoblación) y medioambientales (pérdida de diversidad biológica).

Las propuestas presentadas a esta convocatoria se enmarcan dentro de las Acciones de Innovación $(\mathrm{IA})^{5}$, que son proyectos en colaboración trasnacional destinados a elaborar planes, procesos o servicios nuevos que pueden incluir desarrollo de prototipos, ensayos, demostración, validación de producto a gran escala y réplicas de mercado.

Estas directrices aplicadas al patrimonio dan como resultado un tipo de proyecto a gran escala que busca la participación de múltiples agentes vinculados al patrimonio del sector público y del privado que replique modelos y casos de éxito. Los proyectos se organizan en torno a la figura de role models y de replicators. Los primeros son 
casos de éxito que hayan demostrado vías innovadoras de regeneración, que hayan conseguido la creación de empleo en torno a la puesta en valor del patrimonio, que hayan contribuido al bienestar social y que puedan ser replicados en otros territorios. Los replicators serán esos lugares que, tutorizados por los role models, quieren implementar los modelos en su territorio.

Se ha pasado por tanto del estudio de los bienes aislados al entendimiento del patrimonio como un conjunto de bienes vinculados al territorio, de una política de estudio del bien, a una política de intervención y de "replicabilidad".

El nivel de exigencia para los proyectos es muy alto. Cada propuesta es evaluada por al menos tres expertos independientes en base a tres criterios principales:

$>$ Excelencia. Se debe valorar la claridad y pertinencia de los objetivos, la solidez y credibilidad del concepto y de la metodología planteada, la innovación potencial que muestra, los planteamientos interdisciplinares que la sustenta, entre otros aspectos.

$>$ Impacto esperado

$>$ Cualidad y eficiencia de la implementación del proyecto

Podemos concluir que los proyectos exitosos de esta convocatoria han sido aquellos que:

> Han definido mejor la figura de los role models, escogiendo casos de éxito donde la regeneración del patrimonio cultural esté claramente demostrada

$>$ Han establecido de manera clara como los role models van a asistir a los replicators, como se va a realizar esa transferencia de la buena práctica y como se van a salvar las diferencias territoriales.

$>$ Han especificado los impactos esperados por el proyecto de manera detallada. Se han descartado los proyectos en los que no se especificaba cómo el patrimonio cultural iba a contribuir a la regeneración de los territorios o qué nuevas oportunidades de mercado iba a ofrecer.

\section{NOTAS}

1. Información completa del programa en Guía Horizonte 2020 <http://eshorizonte2020.cdti.es/recursos/ doc/Programas/Cooperacion_internacional/HORIZONTE\%202020/49690_237237201410168.pdf> [Consulta: 05/10/2017]

2. Las posibilidades de financiación de H2020 se establecen según los Programas de Trabajo plurianuales que fijan criterios de admisibilidad, tipos de acciones o criterios de selección. PT 2016-2017<https://ec.europa. eu/programmes/horizon2020/en/what-work-programme> [Consulta: 01/07/2017]

3. Estas directrices son el resultado de las conclusiones del Grupo de Expertos en Patrimonio Cultural recogidas en el informe Getting cultural heritage to work for Europe <http://ec.europa.eu/programmes/horizon2020/en/ news/getting-cultural-heritage-work-europe> [Consulta: 01/07/2017]

4. Las convocatorias de propuestas están divididas en topics relacionados que definen un campo concreto de investigación e innovación sobre el que los solicitantes deben elaborar sus propuestas.

5. Las actividades de H2020 se pueden desarrollar según diversos tipos de acciones, que llevan asociadas tipos de financiación específicos. Más información en las páginas 38 y siguientes de la Guía Horizonte 2020. 